\title{
Rapid Screening Diagnosis of SARS-COV-2 Infection With IgM-igG Combined Antibody Test Using Peripheral Blood
}

\section{Zhengtu Li}

The first affiliated hospital of Guangzhou Medical University

\section{Shaoqiang $\mathrm{Li}$}

The first affiliated hospital of Guangzhou Medical University

\section{Youwei Wang}

Sichuan Academy of Medical Science

\section{Yongkang Liao}

The first affilited hospital of Guangzhou Medical University

\section{Hui Chen}

Shenzhen Bao an District Songgang Peoples Hospital

\section{Jing Cheng}

The first afiiliated hospital of Guangzhou Medical University

Ye Lin

The first affiliated hospital of Guangzhou Medical University

\section{Zhaoming Chen}

The first affiliated hospital of Guangzhou Medical University

\section{Kangjun Sun}

Jiaangsu Medomics Medical Technology Co. Ltd, Nanjing

\section{Min Zhang}

The first affiliated hospital of Guangzhou Medical University

\section{Mindie Wang}

The first affiliated hospital of Guangzhou Medical University

\section{Xinni Wang}

The first affiliated hospital of Guanghzou Medical University

\section{Xinyan Yang}

The first affiliated hospital of Guangzhou Medical University

\section{Wensheng Cai}

Maruzen Yushodo Kabushiki Kaisha

\section{Yangqing Zhan}

The fist affiated hospital of Guangzhou Medical Unoversity

\section{Shiyue Li}


The first affiliated hospital of Guangzhou Medical University

\section{Nanshan Zhong}

The first affiliated hospital of Guangzhou Medical University

Feng Ye ( $\nabla$ tu276025@gird.cn )

The first affiliated hospital of Guangzhou Medical University

\section{Research article}

Keywords: COVID-19, IgM-IgG antibody, peripheral blood, rapid screening

Posted Date: July 8th, 2020

DOl: https://doi.org/10.21203/rs.3.rs-37147/v1

License: (9) This work is licensed under a Creative Commons Attribution 4.0 International License. Read Full License 


\section{Title page}

Rapid screeningdiagnosisofSARS-CoV-2 infectionwith IgM-IgG combined antibody test using peripheralblood 政

5 Zhengtu $\mathrm{Li}^{1 *}$,Shaoqiang $\mathrm{Li}^{1 *}$, YouweiWang ${ }^{2 *}$, Yongkang Liao ${ }^{1}$, Hui Chen ${ }^{3}$, Jing Cheng ${ }^{1}$, Ye Lin ${ }^{1}$, Zhaoming Chen ${ }^{1}$, Kangjun Sun ${ }^{4}$,Min Zhang ${ }^{1}$, Mindie Wang ${ }^{1}$, Xinni Wang ${ }^{1}$, Xinyan Yang ${ }^{1}$, Wensheng $\mathrm{Cai}^{4}$, Yangqing Zhan ${ }^{1}$,Shiyue $\mathrm{Li}^{1}$, Nanshan Zhong ${ }^{1}$,Feng $\mathrm{Ye}^{1 \#}$

${ }^{1}$ State Key Laboratory of Respiratory Disease, National Clinical Research Center for Respiratory Disease, Guangzhou Institute of Respiratory Health, the First Affiliated Hospital of Guangzhou Medical University, Guangzhou 510120, China

${ }^{2}$ Department of Clinical Laboratory, Sichuan Academy of Medical Sciences \& Sichuan Provincial People's Hospital, Chengdu 610072, China

${ }^{3}$ Shenzhen Bao'an District Songgang Peoples' Hospital, Shenzhen 518105, China

${ }^{4}$ Jiangsu Medomics Medical Technology Co., Ltd, Nanjing 210061, China

7

$$
\text { * Contributed equally }
$$

\section{Corresponding to:}

Prof. Feng Ye, the First Affiliated Hospital of Guangzhou Medical University of Guangzhou Medical University,151 Yanjiang Xi Road, Guangzhou, Guangdong 510120, China. Tel.:+86-20-83062898; Fax: +86-20-83062898.E-mail: tu276025@gird.cn, or yefeng@gird.cn. 
Running Title:

Rapidscreening diagnosis forSARS-CoV-2 infection

\section{Key points:}

34

1.There were higher sensitivity and specificity of the rapid IgM-IgG combined antibody test for severe acute respiratory syndrome coronavirus 2 (SARS-CoV-2) using peripheral blood as a point-of-care testing (POCT) assay.

2. The POCT assay also can detect IgM and IgG antibodies of SARS-CoV-2 in asymptomatic carriers.

3. The POCT assaycan be used for rapid screening of SARS-CoV-2 infection.

40

41

42 


\section{Abstract}

Background: Rapid and convenient screening for identification ofSARS-CoV-2 infected individuals are key to prevent and control this pandemic.

Methods: The peripheral blood samples werecollected fromcoronavirus disease 2019(COVID-19) patients and asymptomatic carriersto evaluate the test characteristics of the IgM-IgG combined assay for SARS-CoV-2 compared to that of serum samples and enzyme-linked immuno sorbent assay (ELISA). Close contacts, healthcare workers and workforces wererecruited and screened using this assay.

Results:The sensitivity of the rapid IgM-IgG combined antibody test for SARS-CoV-2 using peripheral blood (sued as a POCT) was $97.0 \%$ and the specificity was $99.2 \%$, which was consistent with the result obtained using serum sample (consistency is about 100\%). Furthermore, this POCT assay also can detect IgM and IgG antibodies of SARS-CoV-2 in asymptomatic carriers, with 19 of the 20 RT-PCR confirmed asymptomatic carriers testing positive. Therefore, this POCT assay was used for population screening of SARS-CoV-2 infection diagnosis. First, it found 4 positive close contacts among the 10 cases, and there were three IgM positive cases and one IgG positive case among them. It is worth noting that the $\operatorname{IgM}$ positive cases also tested positive for the nucleic acid of the SARS-CoV-2. Second, there was one IgM positive assay among the 63 healthcare workers, but RT-PCR of SARS CoV-2 was negative. Third, for workforces screening, there were no positive cases.

Conclusions: The IgM-IgG combined antibody test of SARS-CoV-2 can be used as a POCT for rapid screening of SARS-CoV-2 infection.

Keywords:COVID-19;IgM-IgG antibody; peripheral blood; rapid screening (1)

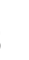
. . 6 i7 


\section{Background}

COVID-19 has spread rapidly around the world since its outbreak in December 2019, leading to more than 10 million cases in over 160 countries up to 29 June 2020,furthermore, the WHO reassessment of global risk was deemed to be very high.[1]And the biggest challenge for effective prevention and control of COVID-19 pandemic was how to quickly and accurately identify both symptomatic and symptomatic carriers of severe acute respiratory syndrome coronavirus-2 (SARS-CoV-2) infection in the general population. Currently, viral nucleic acid real-time polymerase chain reaction (RT-PCR) has been the diagnostic standard for theSARS-CoV-2 infection.[2, 3] However, the currentRT-PCR assays have many limitations: 1). although RT-PCR is rapid and sensitive/specific, it has a long turnaround time andis operationally complicated, often taking upwards of 2-3 hours to produce results; 2)RT-PCR testing requires certified laboratories, expensive equipment and highly-trained technicians to perform the assay; 3) RT-PCR may produce false negative results, $[4,5]$ andthere are considerable differences in sensitivity of RT-PCR for different specimens.[6] As a result, RT-PCR is not suitable to be a POCT test for rapid screening of SARS-CoV-2 infection.

Blood specific antibodies, including IgM and IgG of SARS-CoV-2, have also been used for the diagnosis of SARS-CoV-2 infection.[2, 3] Specific antibody testing for SARS-CoV-2 has been as an ideal choice for the diagnosis of COVID-19 as it is simple to conduct and has both a quick turnaround time and high sensitivity. It is widely accepted that IgM provides the initial humoral immune response during viral infections, prior to the generation of the adaptive, high affinity $\mathrm{IgG}$ antibodies that are important for long term immunity and immunological memory.[7] The acute antibody response to SARS-CoV-2 infection is similar to many other acute viral infections.[8, 9] After the body has been infected with SARS-CoV-2, IgM antibodies are produced, such that increases in the level of $\operatorname{IgM}$ are markers of a recent infection. The production of $\operatorname{IgG}$ antibodies occurs later in the disease course and is an indicator of previous infections. The simultaneous detection of $\operatorname{IgM}$ antibody and $\operatorname{IgG}$ antibody can distinguish acute and previous infections[8]. Thus, the rapid detection of both IgM and IgG antibodies 
will add value to the diagnosis and treatment of COVID-19. In our previous study, we have designed a rapid $\operatorname{IgM}-\operatorname{IgG}$ combined antibody test kit for diagnosis of SARS-CoV-2 infection. It also has been that the test can be performed rapidly ( $<15 \mathrm{~min}$ ) and conveniently using peripheral blood samples to detectSARS-CoV-2 infection.[10] However, there were some limitations in our previous study: 1) insufficient number of COVID-19 cases using peripheral blood sampling 2) lack of data to confirm that it can be used for asymptomatic carriers diagnosis, 3) and for as a POCT detection, and screening for SARS-CoV-2 infection. Therefore, we designed and carried out this study to address these limitations using $\operatorname{IgM}-\operatorname{IgG}$ combined antibody test.

\section{Methods}

\section{Study oversight and design}

A flowchart outlining the milestones in the study is shown in Figure 1.

\section{Targeted testing}

COVID-19 patients, confirm by RT-PCRpositive of SARS-CoV-2 and whos' clinical and virological characteristicswill be reported in other papers, were recruited in the study to determinethe efficacy of IgM-IgG combined antibody test. The group included both symptomatic individuals, who haveclinical symptoms of cough, fever, myalgias, or shortness of breath, and the onset time more than seven days before antibody tested, and asymptomatic carriers who confirmed by RT-PCRpositive of SARS-CoV-2.

\section{Population screening}

Population screening focused on the following three groups of individuals: 1) closecontacts either symptom-free or had mild symptoms, but had contact withconfirm COVID-19 patients. 2) Healthcare workers who took care COVID-19 patients for extended periods of time. 3) Workforces who hadrecentexposure to high-risk areas and needed to be ruled out SARS-CoV-2 infection before returning to work. Before $\operatorname{IgM} / \operatorname{IgG}$ test, all participants were required to self-quarantine for more than 14 days either after last contact with confirmedCOVID-19 patients or come from high-risk areas. 
Participants positive for SARSCoV-2 were required to self-quarantine, then they were retested by RT-PCR assay for SARS-CoV-2. If the RT-PCR results were positive,

149 they continued to be quarantined and treated until they were RT-PCR negative.

150

151

152

153

154

\section{IgM and IgG antibody of SARS-CoV-2 was detected}

\section{Peripheralblood testing}

Just prior to testing, the pouched device was opened. and an alcohol disinfected finger from the study subject was pricked with a disposable needle. Approximately one drop of blood (about $15 \mu \mathrm{L}$ ) was squeezed out and pipetted into the sample port to which 2-3 drops (70-100 ul) of dilution buffer was added to drive capillary action along the strip. Results were obtained 10-15 minutes later (Fig. 2).

\section{ELISA assay}

Anti-Human IgM ( $\mu$-chain specific) antibody or N protein of SARS-CoV-2 (IgG) was used as the coating. The plasma obtained from patients was diluted at 1:100 for testing. HRP labeled N protein of SARS-CoV-2 $(\operatorname{IgM})$ or anti-human $\operatorname{IgG}(\mathrm{H}+\mathrm{L})$ antibody labeled with HRP was used as the secondary antibody. The colorimetric reaction was induced by adding TMB and terminated by using $\mathrm{H}_{2} \mathrm{SO}_{4}$. Detection of the substrate was carried out via spectrometry by measuring the OD450. The positive and negative control were set at the same time.

\section{Real-time reverse transcriptase polymerase chain reaction (RT-PCR) assay}

Clinical specimens were tested with RT-PCR assay kits certified by the Chinese government (Kaijie biotechnology co., LTD, Shanghai, China). The detailed product information, specifically the detection sequence ofSARS-CoV-2, could not be fully obtained due to proprietary technology. However, it is known that the detection target of RT-PCR for SARS-CoV-2 focuses on NP and ORF1ab genes, anda positive result requires both gene tests to be positive. The detection operation was conducted in accordance with the instructions of the products.

\section{Statistical analysis}

The sensitivity, specificity, the overall coincidence rate and Kappa statistical test which was used for the interobserver consistency are calculated according to the following 
formulas

1) Sensitivity $=\frac{\mathrm{TP}(\text { Ture positive })}{\mathrm{TP}+\mathrm{FN}(\text { False negative })} \times 100 \%$

2) Specificity $=\frac{\mathrm{TN}(\text { Ture negative })}{\mathrm{FP}(\text { False positive })+\mathrm{TN}} \times 100 \%$.

3) The overall coincidence rate is expressed by the $\frac{\mathrm{TP}+\mathrm{TN}}{\mathrm{TP}+\mathrm{FP}+\mathrm{FN}+\mathrm{TN}} \times 100 \%$ ratio

4) Kappa consistency was calculated by $\frac{\mathrm{PA}-\mathrm{Pe}}{1-\mathrm{Pe}}$, in which $\mathrm{PA}=\frac{\mathrm{TP}+\mathrm{TN}}{\mathrm{TP}+\mathrm{FP}+\mathrm{FN}+\mathrm{TN}}, \mathrm{Pe}=$ $\frac{(\mathrm{TP}+\mathrm{FP})(\mathrm{TP}+\mathrm{FN})+(\mathrm{FN}+\mathrm{TN})(\mathrm{FP}+\mathrm{TN})}{(\mathrm{TP}+\mathrm{FP}+\mathrm{FN}+\mathrm{TN}) \times(\mathrm{TP}+\mathrm{FP}+\mathrm{FN}+\mathrm{TN})}$. Results were accepted as either poor $($ kappa $<0.20)$, fair $($ kappa $=0.21-0.40)$, moderate $($ kappa $=0.41-0.60), \operatorname{good}(\operatorname{kappa}=0.61-0.80)$, very good $($ kappa $=0.81-0.90)$, and excellent $($ kappa $>0.91)$

\section{Results}

IgM-IgG combined antibody test showed a higher sensitivity and specificity for SARS-CoV-2 in confirmed COVID-19 patients using peripheralblood

In order to evaluate whether the $\operatorname{IgM}-\operatorname{IgG}$ combined antibody test can detect specific antibodies ofSARS-CoV-2 using peripheralblood,samples from confirm COVID-19 (RT-PCR positive of SARS-CoV-2), non-COVID-19 patients (RT-PCR negative of SARS-CoV-2) and healthy were recruited.

A totalof 85 cases were tested: 33 confirmed COVID-19 patients, 23 non-COVID-19 patients and 29 healthy subjects. The IgM/IgG tested time of confirm COVID-19 patients was average $35 \pm 8.5$ days postsymptom onset (Supplementary Table 1), and it was average 2.1 \pm 0.9 days post symptom onset for non-COVID-19 patients. Furthermore, 19 of 33 confirm COVID-19 patients were IgM positive (sensitivity $57.6 \%$ ), and the test was most negative in both non-COVID-19 and healthy individuals (specificity 98.5\%). TheIgG antibody test results showed a sensitivity of $97.0 \%$ and a specificity of $99.2 \%$, with 32 of the 33 COVID-19 patientstested positive(Table 1).These operations usedperipheral blood.

We also evaluated the differences in test characteristics of the $\operatorname{IgM}-\operatorname{IgG}$ combined antibody assay between peripheralblood and serum samples, as well as between the combined antibody assay and ELISA. As shown in Table 2, the overall coincidence rate 
between peripheralblood and serum samples was $100 \%$ for $\operatorname{IgM}$ and $\operatorname{IgG}$ antibody testing. Furthermore, compared to ELISAassay, the overall coincidence rate was $80 \%$ (16 out of 20) for the IgM-IgG combined antibody test. Among the 16 patients, 4 patients were both $\operatorname{IgM}$ and $\operatorname{IgG}$ positive, 5 were $\operatorname{IgM}$ positive and $\operatorname{IgG}$ negative,7 were IgM negative and IgG positive (Fig. 3).

IgM-IgG combined antibody test of SARS-CoV-2 also showed a positive diagnosis for asymptomatic carriers using peripheral blood

This study recruited 20 asymptomatic carriers who had no clinical symptoms or travel history of high-risk area. They were permanent residents in Sichuan province, China. However, they had closecontact with confirmed COVID-19 patients in their community within 14 days and werepositive for SARS-CoV-2 by RT-PCR. Subsequently, they got the $\operatorname{IgM}$ and $\operatorname{IgG}$ antibodies tested at 5.8 \pm 2.87 days (4-14 days) after the initial positive PCR assay using peripheralblood samples. The total positive rate was $95 \%$ as compared to RT-PCR. The positive rate of single IgM and IgM-IgG combinedwere higher than that of single $\operatorname{IgG}, 95 \%$ v.s $95 \%$ v.s $30 \%$, respectively (Table 3). The results verified that the IgM-IgG combined antibody test can be used to diagnose asymptomatic SARS-CoV-2 carriers.

IgM-IgG combined antibody test can be used as a screening test for SARS-CoV-2 infection

The above results proved that the IgM-IgG combined antibody test can test the $\operatorname{IgM}$ and IgG antibody of SARS-CoV-2 in 10-15 minutesusing peripheral blood as a POCT. Furthermore, this POCT assay can test the antibody in symptomatic and asymptomatic individuals confirmed by RT-PCR. Therefore, we suggest that this POCT assay can be sued for screening diagnosis of SARS-CoV-2 infection in publication. In order to illustrate its screening characteristics, three distinct groups of individualswere included in this study (Fig. 4A). The first group were 10subjects who have an explicit contact history with confirmed COVID-19 patients without proper protective gear, among whom, 3 cases (30\%) were IgM positive but asymptomatic, as well as the RT-PCR retesting of SARS-CoV-2also was positive., And 1 case $(33.3 \%)$ 
was reported IgG positive but RT-PCR negative. Those RT-PCR positive patients received standard treatment afterwards(Fig. 4B). The second group were 63healthcare workers who were in closecontact with COVID-19 patients but wore standard personal protective gear, among whom one showed positive (2.12\%). Re-testing using RT-PCRassayfor SARS-CoV-2 showed negative for this individual although, she was advised to quarantinefor her previous close contact with confirmed COVID-19 patients (Fig. 4B). The third group were 298workforcesfrom high-risk areas. All subjects tested negative and were considered noninfectious and cleared to return to work (Fig. 4B).

\section{Discussion}

We evaluated the rapid screening diagnosis of SARS-CoV-2 infection with IgM-IgG combined antibody test using peripheralblood based on previous validated study [10]. We affirmed that therapid IgM-IgG combined antibody test for SARS-CoV-2using peripheralblood(used as a POCT) presented high sensitivity and specificity compared with serum samples and ELISA. Furthermore, the POCTassay can be used to test the IgM and IgGantibody of SARS-CoV-2 in both symptomatic and asymptomatic individuals. Therefore, we recommend this POCT assay as a screening tool for those potentially exposed to SARS-CoV-2 in a hope to actmore efficiently in the prevention and control of this pandemic.

The current techniques to detect SARS-CoV-2 can be classified into four types based on methodology: pathogen culture, antigen testing, nucleic acid testing and antibody testing. Pathogen culture has traditionally been considered as the goldstandard for viral detection for more than 70years.[11] However, it has limited use because of its slow turnaround time when rapid pathogen detection is required.[12]Although nucleicacid amplification tests including RT-PCR are rapid, highly sensitive and specific,[13, 14]PCR testing requires certified laboratories, expensive equipment, and well-trained technicians, taking 2-3 hours to obtain results. Furthermore, RT-PCR may yield false negative results.[4, 5]Metagenomic 
next-generation sequencing (NGS)has been widely usedas an emerging detection technology, butit requires the sequencing process to be completed before analysis canbegin.[15]Metagenomic NGS also requires cumbersome instruments and a dedicated laboratory. Antigen testing may be able to fit screening, however there are no commercially available products yet. In this occasion, the IgM-IgG combined antibody test of SARS-CoV-2 can be used to address current needs.[10] We were able to verify the utility of this bedside antibody test indetecting the $\operatorname{IgM}$ and $\operatorname{IgG}$ antibodies of SARS-CoV-2 using peripheral blood(Fig. 2). The results can be obtained within 15 minutes with high sensitivity and specificity (Table 1), which is consistent with the previous study.[16]The results obtained from peripheral blood were highly consistent with those from serum samples, which implies that the sampling process can be optimized. The above findings suggest that the rapid IgM-IgG combine antibody test can be employed as a POCT for screening COVID-19 patients. [17]

It has been well established that the initial production of $\operatorname{IgM}$ after a viral infection is followed by $\mathrm{IgG}$, which confers along term immunity and immunological memory.[7]According to other coronavirus infections such as SARS-CoV-1, IgM antibodies can be detected in blood samples 3-6 days after the initial infection and $\operatorname{IgG}$ after 8 days.[18, 19] In COVID-19 patients, IgM are typically produced within 7 days after the onset of illness, but $\operatorname{IgG}$ single positive and $\operatorname{IgM-IgG}$ double positive can appear in the acute and convalescence periods (1-35d).[16]Zhao et al found that less than $40 \%$ of patients had detectable antibodies within 7 days of disease onset, and this portion increased to $100 \%$ after 15 days from initial onset, of which $94.3 \%$ was detected for IgM and 79.8\% for IgG.[8]Herein, we found that the detection sensibility was lower in individual IgM antibody test than individual IgG or IgG-IgM combined antibody test when the testing time was later from onset (Table 1; average $35 \pm 8.5$ days). However, the detection sensibility of individual IgMand IgG-IgM combined antibody testwill be higher than individual IgG when the testing time was early from onset (Table 3; average 5.8 \pm 2.87 days). Additionally, we found that the detection sensibility was higher in IgG-IgM combined antibody test than in individual $\operatorname{IgG}$ or $\operatorname{IgM}$ antibody 
test.[10] Therefore, combined with the production of $\operatorname{IgM}$ and $\operatorname{IgG}$ antibody, we recommend the IgM-IgG combined antibody testwill be better used.

The IgMand IgGantibodies of COVID-19 serve as an indicator of infection. Based on the current understanding of the disease process in China, the Chinese clinical guideline considers the detection of antibodies a diagnostic option for COVID-19.[2]Besides, we believe the rapid $\operatorname{IgM}-\operatorname{IgG}$ combined antibody test of SARS-CoV-2may play an important role in screening individualswith potential exposure to the virus, particularly the asymptomatic carriers.Relevant reports indicate asymptomatic carriers can still transmit the virus to others individuals.[20, 21] Therefore,large scale screening for asymptomatic carriers combined with early detection, quarantine, prevention, and treatment will be crucial to control this epidemic.[22] Fortunately, we found that the rapid IgM-IgG combined antibody test of SARS-CoV-2 could serve as a better testing tool for asymptomatic carriers (Table 3). It is showed that asymptomatic carriers of COVID-19 are highly contagious, and people in close contact with them are susceptible to infection. Therefore, it is important to identify and isolate of asymptomatic carriers of COVID-19, more testing and more follow-up, which is benefit to the prevention and control of the epidemic.[23-25] Interestingly, the rapid IgM-IgG combined antibody test of SARS-CoV-2 has better practical application for the screening of asymptomatic patients, and guided isolation therapy in advance (Fig. 4).

There are limitations to userapid $\operatorname{IgM}-\operatorname{IgG}$ combined antibody test of SARS-CoV-2as a screening tool.Firstly, there will be false negative results as its lower sensitivity compared to that of ELISA (Table 2). Secondly, since IgM and IgG are produced later(usually 3-5 days after onset) in the disease course, early negative results do not rule out an infection. Third, false positive of $\operatorname{IgM}$ and $\operatorname{IgG}$ antibody testing should not be ignored. Therefore, multiple detection methods can be used to improve the diagnostic accuracy when necessary.

\section{Conclusion}

The rapid IgM-IgG combined antibody test for SARS-CoV-2 provides high sensitivity 
and specificity using peripheralbloodsamples as a POCT, which can also be used to detect the antibodies in asymptomatic carriers of the SARS-CoV-2 virus, Therefore, it can be used as a POCT tool to screen the high-risk populations.

\section{Abbreviations}

SARS-CoV-2: severe acute respiratory syndrome coronavirus 2; POCT: point-of-care testing assay; COVID-19):coronavirus disease 2019;ELISA: enzyme-linked immuno sorbent assay; RT-PCR: real-time polymerase chain reaction; NGS: next-generation sequencing.

\section{Declaration}

\section{Consent for publication:}

Not applicable.

\section{Ethics approval and consent for participate:}

This observational study was obtained ethical approvalfrom the Ethics Committee of the First Affiliated Hospital of Guangzhou Medical University (Ethical number: 2020-36), and the informed consent was obtainedfromeach participant.

\section{Availability of data and material:}

The data that support the findings of this study are available from the corresponding author on reasonable request. Participant data without names and identifiers will be made available after approval from the corresponding author. After publication of study findings, the data will be available for others on request. The research team will provide an email address for communication once the data are approved for sharing with others. A proposal containing a detailed description of study objectives and statistical analysis plan will be needed for evaluating the reasonability of request for our data. The corresponding author will make a decision based on these materials. Additional materials may also be required during the process. 


\section{Funding:}

This work was funded by the Scientific and Technological Emergency Special of Guangdong Province for Prevention and Controlling of COVID-19 (Grant number: 2020B1111340004); the Emergency Project of COVID-19 Clinical Research on Prevention and Treatment withTraditional Chinese Medicine (TCM) in the Guangdong Bureau of TCM (Grant number: 2020ZYYJ05).Funds come from government agencies. However, they only provide funding, yet there is no interference with the research. Furthermore, there is no conflict of interest between us with government agencies.

\section{Competing interests:}

The authors report no conflicts of interest.

\section{Authors' contributions:}

FY, SQL, YWW and ZTL conceived and designed the study, had full access to all data, and took responsibility for the data accuracy and integrity.CJ, YL, ZMC, MZ, KJS, WSC and MDW contributed to the population screening. YWW and ZMC contributed to the RT-PCR test. FY and ZTL contributed to the statistical analysis. The remaining authors contributed to the management and treatment of patients.All authors contributed to data acquisition, data analysis, or data interpretation, and reviewed and approved the final version of the manuscript.

\section{Acknowledgments}

This work was funded by the Guangzhou Institute of Respiratory Health. We thank the patients; healthcare professionals who care for the patients; close contact, healthcare workers and workforcewho participated in this study; we appreciate staffs at the clinical laboratory; technicians from the State Key Laboratory of Respiratory Disease for their excellent assistance; we thank staffs at Guangdong Centers for Disease Control (CDC) for the diagnosis of SARS-CoV-2.

\section{References}


1. Organization WH: Coronavirus disease 2019 (COVID-19) Situation Report - 161 https://www.who.int/docs/default-source/coronaviruse/situation-reports/20200629-cov id-19-sitrep-161.pdf?sfvrsn=74fde64e_2.Data as received by WHO from national authorities by 10:00 CEST, 29 June 2020 .

2. Prevention CCfDCa: The guideline of diagnosis and treatment of COVID-19 (the seventh edition).

http://wwwchinacdccn/jkzt/crb/zl/szkb_11803/jszl_11815/202003/t20200305_214142ht $m / 2020$.

3. Organization TWH: Clinical management of severe acute respiratory infection when novel coronavirus ( $\mathrm{nCoV}$ ) infection is suspected.

https://wwwwhoint/publications-detail/clinical-management-ofsevere-acute-respirator $y$-infection-when-novel-coronavirus-(ncov)-infection-is-suspected (accessed Feb 8 , 2020) Jan 11, 2020.

4. Yvonne CF Su, Danielle E Anderson, Barnaby E Young, Feng Zhu, Martin Linster, Shirin Kalimuddin, Jenny GH Low, Zhuang Yan, Jayanthi Jayakumar, LouisaSun et al: Discovery of a 382-nt deletion during the early evolution of SARS-CoV-2. bioRxiv preprint doi: https://doiorg/101101/202003119872222020.

5. Ai T, Yang Z, Hou H, Zhan C, Chen C, Lv W, Tao Q, Sun Z, Xia L: Correlation of Chest CT and RT-PCR Testing in Coronavirus Disease 2019 (COVID-19) in China: A Report of 1014 Cases. Radiology 2020:200642.

6. Wang W, Xu Y, Gao R, Lu R, Han K, Wu G, Tan W: Detection of SARS-CoV-2 in Different Types of Clinical Specimens. JAMA 2020.

7. Racine R, Winslow GM: IgM in microbial infections: taken for granted? /mmunology letters 2009, 125(2):79-85.

8. Zhao J, Yuan Q, Wang H, Liu W, Liao X, Su Y, Wang X, Yuan J, Li T, Li J et al: Antibody responses to SARS-CoV-2 in patients of novel coronavirus disease 2019. Clin Infect Dis 2020.

9. To KK, Tsang OT, Leung WS, Tam AR, Wu TC, Lung DC, Yip CC, Cai JP, Chan JM, Chik TS et al: Temporal profiles of viral load in posterior oropharyngeal saliva samples and serum antibody responses during infection by SARS-CoV-2: an observational cohort study. Lancet Infect Dis 2020.

10. Li Z, Yi Y, Luo X, Xiong N, Liu Y, Li S, Sun R, Wang Y, Hu B, Chen W et al: Development and clinical application of a rapid IgM-IgG combined antibody test for SARS-CoV-2 infection diagnosis. J Med Viro/ 2020.

11. Mc IJ: Emergency Pathology Service. Lancet 1946, 1(6401):669.

12. Charalampous T, Kay GL, Richardson H, Aydin A, Baldan R, Jeanes C, Rae D, Grundy S, Turner DJ, Wain J et al: Nanopore metagenomics enables rapid clinical diagnosis of bacterial lower respiratory infection. Nat Biotechno/ 2019, 37(7):783-792.

13. Hassibi A, Manickam A, Singh R, Bolouki S, Sinha R, Jirage KB, McDermott MW, Hassibi B, Vikalo $\mathrm{H}$, Mazarei $\mathrm{G}$ et al: Multiplexed identification, quantification and genotyping of infectious agents using a semiconductor biochip. Nat Biotechno/2018, 36(8):738-745.

14. Buchan BW, Ledeboer NA: Emerging technologies for the clinical microbiology laboratory. Clin Microbiol Rev 2014, 27(4):783-822. 
15. Tausch SH, Strauch B, Andrusch A, Loka TP, Lindner MS, Nitsche A, Renard BY: LiveKraken--real-time metagenomic classification of illumina data. Bioinformatics 2018, 34(21):3750-3752.

16. Wenjian, Z, Xin, L, Chi, H, Ming, W, Shunqing, L, Huali, P, Wenwen, P, Yongjin, W, Jie, $M$, Zhongtao, $\quad G$ et al: Clinical Evaluation and Application of Detection for SARS-CoV-2 IgM and IgG Antibodies with Colloidal Gold Immunochromatography Assay. Chinese Journal of Virology 2020.

17. Garvey MI, Biggs M, Reddy-Kolanu V, Flavell H, Wallett A, Holden E: Lessons learnt from influenza POCT implementation in an acute medical unit. J Hosp Infect 2019, 103(3):358-360.

18. Lee HK, Lee BH, Seok SH, Baek MW, Lee HY, Kim DJ, Na YR, Noh KJ, Park SH, Kumar DN et al: Production of specific antibodies against SARS-coronavirus nucleocapsid protein without cross reactivity with human coronaviruses 229E and OC43. J Vet Sci 2010, 11(2):165-167.

19. Wan ZY ZX, Yan XG IFA in testing specific antibody of SARS coronavirus. South China J Prev Med 2003, 29(3):36-37.

20. Rothe C, Schunk M, Sothmann P, Bretzel G, Froeschl G, Wallrauch C, Zimmer T, Thiel V, Janke C, Guggemos W et al: Transmission of 2019-nCoV Infection from an Asymptomatic Contact in Germany. N Eng/ J Med 2020.

21. Zou L, Ruan F, Huang M, Liang L, Huang H, Hong Z, Yu J, Kang M, Song $Y$, Xia J et al: SARS-CoV-2 Viral Load in Upper Respiratory Specimens of Infected Patients. N Eng/ J Med 2020.

22. Guan WJ, Chen RC, Zhong NS: Strategies for the prevention and management of coronavirus disease 2019. Eur Respir J2020, 55(4).

23. Zou L, Ruan F, Huang M, Liang L, Huang H, Hong Z, Yu J, Kang M, Song Y, Xia J et al. SARS-CoV-2 Viral Load in Upper Respiratory Specimens of Infected Patients. N Eng/ J Med 2020, 382(12):1177-1179.

24. Hu Z, Song C, Xu C, Jin G, Chen Y, Xu X, Ma H, Chen W, Lin Y, Zheng Y et al: Clinical characteristics of 24 asymptomatic infections with COVID-19 screened among close contacts in Nanjing, China. Sci China Life Sci 2020, 63(5):706-711.

25. Zhang J, Wu S, Xu L: Asymptomatic carriers of COVID-19 as a concern for disease prevention and control: more testing, more follow -up. Biosci Trends 2020.

\section{Figure legends}

Figure 1. Study Design for Targeted Testing and Population Screening. In this study, targeted testing for coronavirus disease 2019 (COVID-19) was applied to those with symptoms as well as asymptomatic carriers, as well as for screening for the contact tracing, medical workers, and company staff, who were high-risk populations. 
$478 \quad$ Tables

479

Figure 2. Operating procedure of detecting antibody in peripheral blood. The procedure was simple and convenient, and results can be obtained within 15 minutes.

Figure 3. Comparing the detection characteristics between ELISA and the rapid antibody test. The quadrate (earthy yellow) represents the ELISA assay and the circle represents the rapid antibody test. IgM antibody testing is depicted in red and $\operatorname{IgG}$ antibody testing is depicted in orange-yellow.

Figure 4.Population screening with rapid IgM-IgG combined antibody test for SARS-CoV-2 in peripheral blood. A was a picture showed the screening site. B shows the screening results, including Close contacts, healthcare workers and workforces.

\begin{tabular}{|c|c|c|c|c|c|c|c|}
\hline \multicolumn{3}{|c|}{ Variable } & \multicolumn{3}{|c|}{ PCR } & \multirow[t]{2}{*}{ Sensibility } & \multirow[t]{2}{*}{ Specificity } \\
\hline & & & Positive & Negative & Total & & \\
\hline \multirow{7}{*}{ IgM } & COVID 10 & Positive & 19 & 0 & 19 & \multirow{7}{*}{$57.6 \%$} & \multirow{7}{*}{$98.5 \%$} \\
\hline & & Negative & 14 & 0 & 14 & & \\
\hline & Non-COVID- & Positive & 0 & 2 & 2 & & \\
\hline & 19 & Negative & 0 & 99 & 99 & & \\
\hline & \multirow{3}{*}{$\begin{array}{l}\text { Healthy } \\
\text { person }\end{array}$} & Positive & 0 & 0 & 0 & & \\
\hline & & Negative & 0 & 29 & 29 & & \\
\hline & & Total & 33 & 130 & 163 & & \\
\hline \multirow{4}{*}{ IgG } & \multirow{2}{*}{ COVID-19 } & Positive & 32 & 0 & 32 & \multirow{4}{*}{$97.0 \%$} & \multirow{4}{*}{$99.2 \%$} \\
\hline & & Negative & 1 & 0 & 1 & & \\
\hline & \multirow{2}{*}{$\begin{array}{l}\text { Non-COVID- } \\
19\end{array}$} & Positive & 0 & 1 & 1 & & \\
\hline & & Negative & 0 & 100 & 100 & & \\
\hline
\end{tabular}




\begin{tabular}{|c|c|c|c|c|c|c|c|}
\hline & \multirow{3}{*}{$\begin{array}{l}\text { Healthy } \\
\text { person }\end{array}$} & Positive & 0 & 0 & 0 & & \\
\hline & & Negative & 0 & 29 & 29 & & \\
\hline & & Total & 33 & 130 & 163 & & \\
\hline & COVID 10 & Positive & 32 & 0 & 32 & & \\
\hline & COVID-19 & Negative & 1 & 0 & 1 & & \\
\hline & Non-COVID- & Positive & 0 & 3 & 3 & & \\
\hline $\begin{array}{l}\text { IgM } \\
\text { /IoG }\end{array}$ & 19 & Negative & 0 & 98 & 98 & $97.0 \%$ & $97.7 \%$ \\
\hline & Healthy & Positive & 0 & 0 & 0 & & \\
\hline & person & Negative & 0 & 29 & 29 & & \\
\hline & & Total & 33 & 130 & 163 & & \\
\hline
\end{tabular}

483 Noting:1) The IgM and IgG tested time was average $35 \pm 8.5$ days post symptom onset.

4842 2) $\operatorname{IgM} / \operatorname{IgG}$ means IgM positive or/and $\mathrm{IgG}$ positive.

485

486

487

488

489

490

491

492

493

494

495

496

497

498

499

Table 2. The comparing between peripheral blood and serum of venous blood of

500

SARS-CoV-2 IgM-IgG combined antibody test

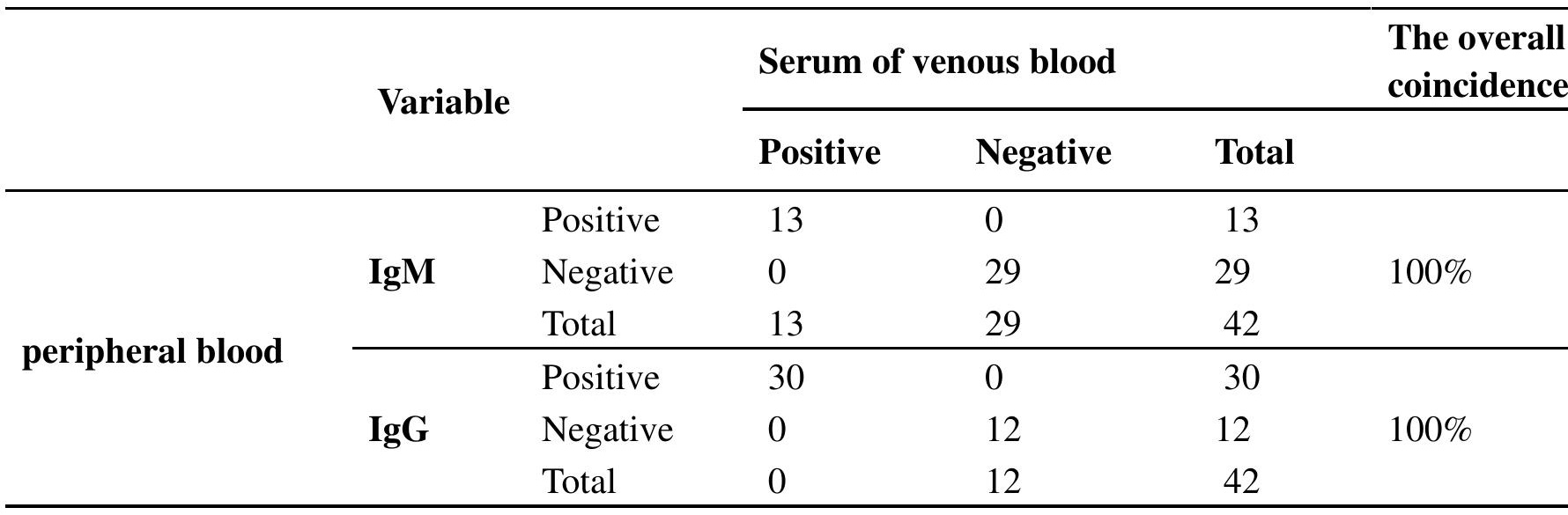


Table 3. IgM-IgG combined antibody detection of SARS-CoV-2 in asymptomaticcarriers

\begin{tabular}{ll}
\hline Variable & Asymptomatic carriers \\
\hline Male sex, no. $(\%)$ & $8 / 20(40)$ \\
\hline Mean age (years) & $25.2 \pm 12.79$ \\
\hline Nationality & China \\
\hline Place of residence & Sichuan province \\
\hline Anyepidemic area travel, no. $(\%)$ & $0 / 20(0)$ \\
\hline Known contact with infected person, no. $(\%)$ & $20 / 20(100)$, cluster cases \\
\hline The time contacting & No clear \\
\hline Symptoms reported, no. $(\%)$ & $0 / 20(0)$ \\
\hline RT-PCR positive, no. $(\%)$ & $20 / 20(100)$ \\
\hline Antibody testing, no. $(\%) ;$ & IgM (+) $\quad$ IgG (+) $\quad$ IgM or IgG (+) \\
\hline using peripheral blood & $19 / 20(95) \quad 6 / 20(30) \quad$ 19/20 (95) \\
\hline The time to take results & $10-15$ min \\
\hline Time distance from RT-PCR positive (days) & $5.8 \pm 2.87$ \\
\hline
\end{tabular}


Figures

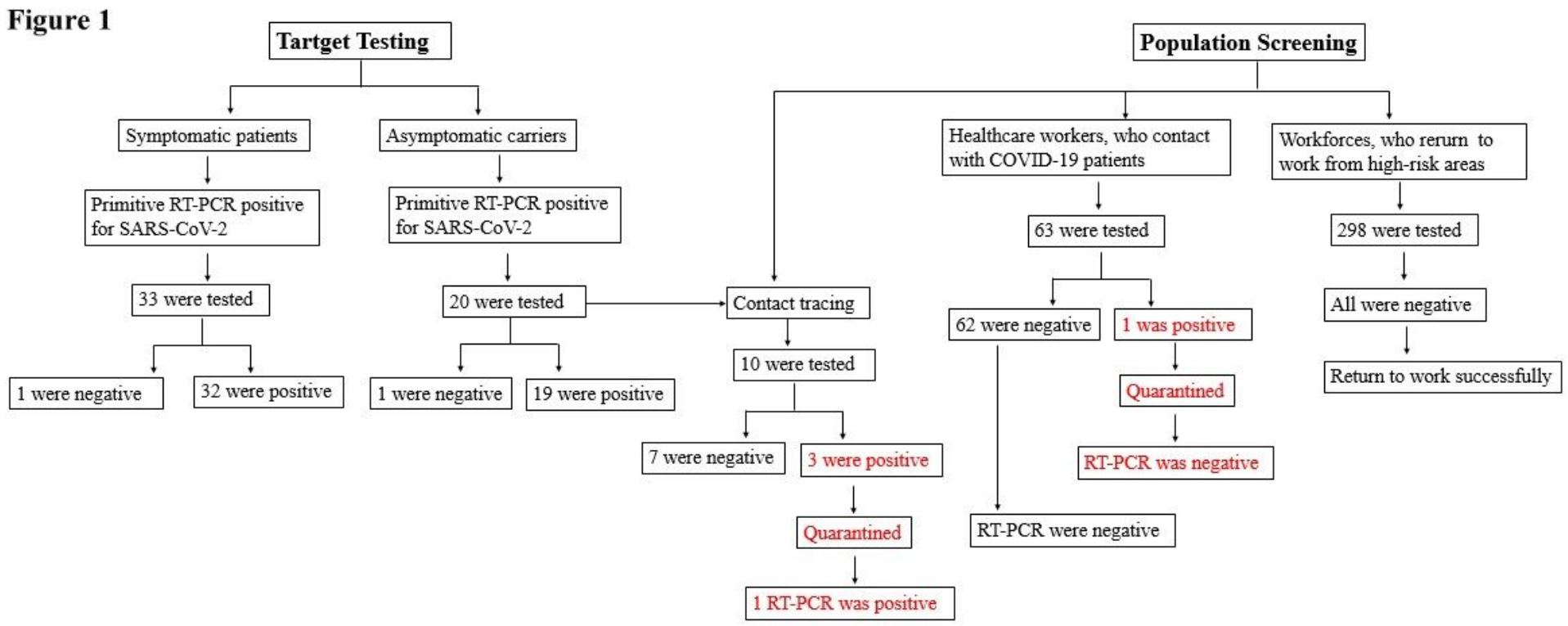

\section{Figure 1}

Study Design for Targeted Testing and Population Screening. In this study, targeted testing for coronavirus disease 2019 (COVID-19) was applied to those with symptoms as well as asymptomatic carriers, as well as for screening for the contact tracing, medical workers, and company staff, who were high-risk populations.

\section{Figure 2}

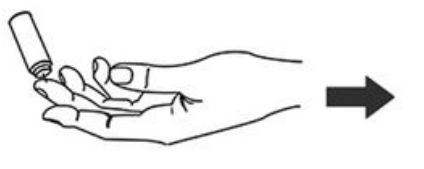

\section{$15 \mu \mathrm{L}$ blood}

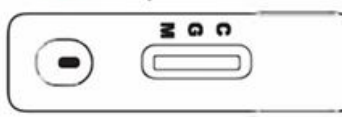

\section{Drops of buffer}

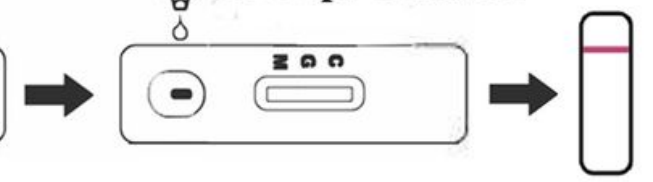

Negative
Results in 10-15 minutes

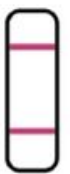

IgM

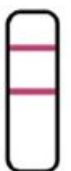

IgG

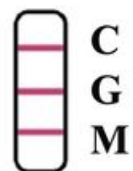

IgM/IgG
Positive Positive Positive

\section{Figure 2}

Operating procedure of detecting antibody in peripheral blood. The procedure was simple and convenient, and results can be obtained within 15 minutes. 


\section{Figure 3}

\section{Total: 20}

\section{ELISA}

4 (IgM-/IgG-)

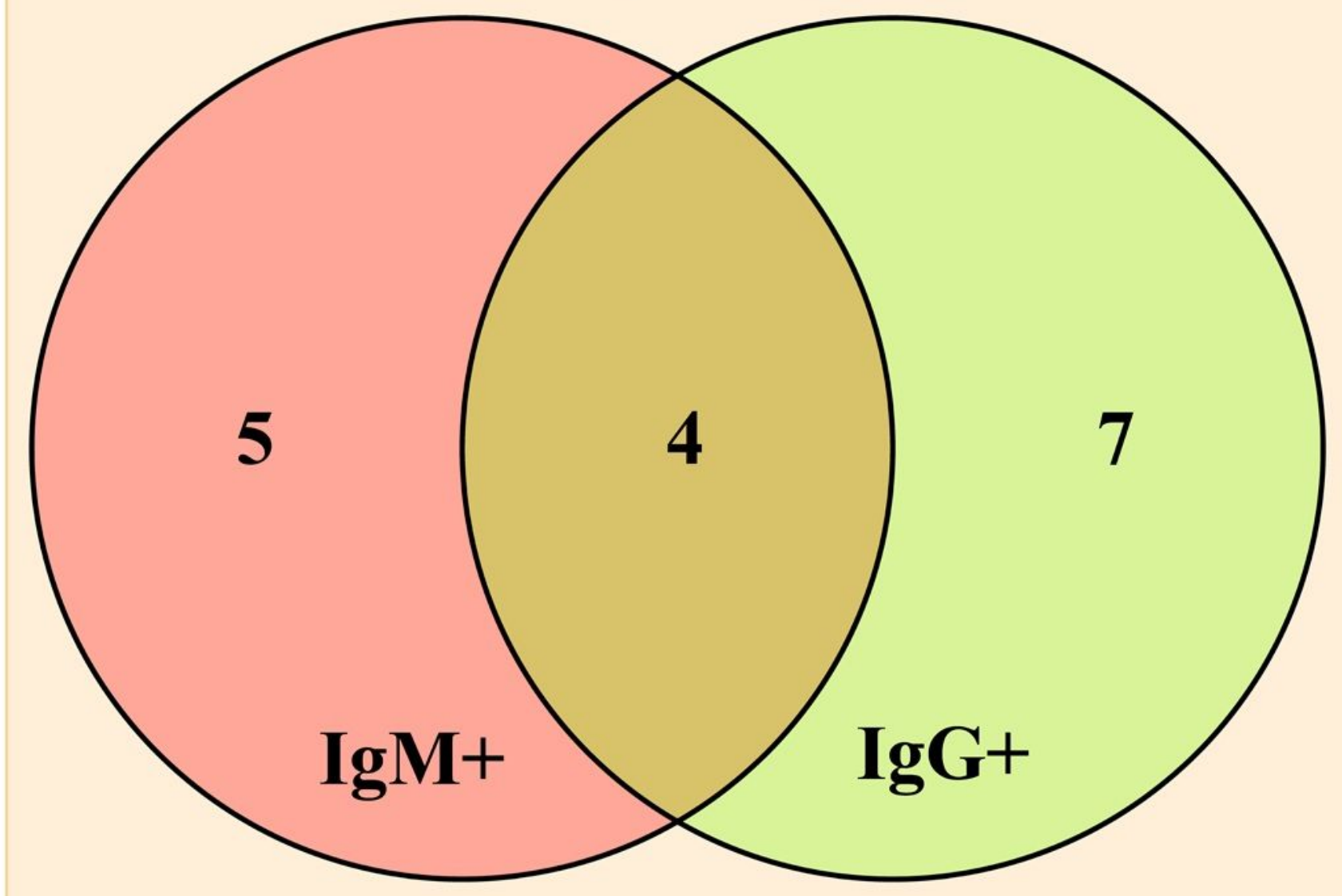

Figure 3

Comparing the detection characteristics between ELISA and the rapid antibody test. The quadrate (earthy yellow) represents the ELISA assay and the circle represents the rapid antibody test. IgM antibody testing is depicted in red and IgG antibody testing is depicted in orange-yellow. 
Figure 4

A

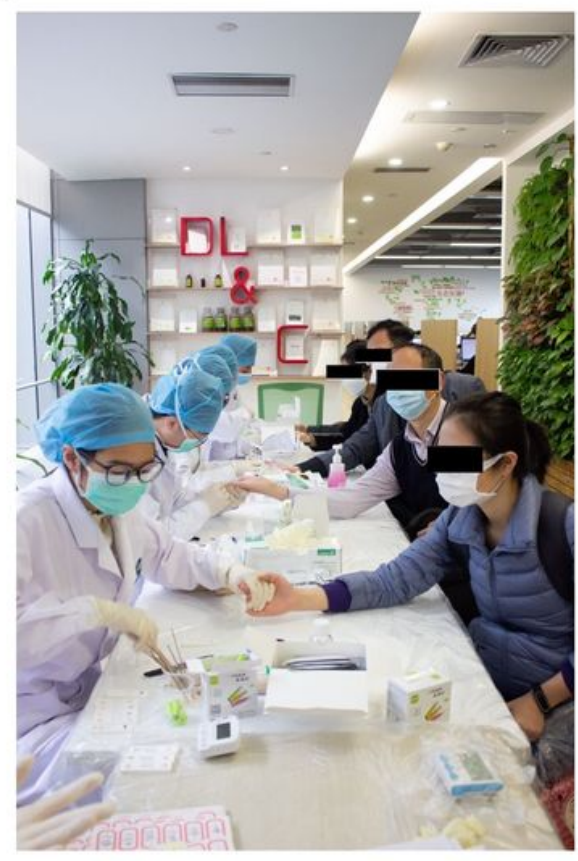

B

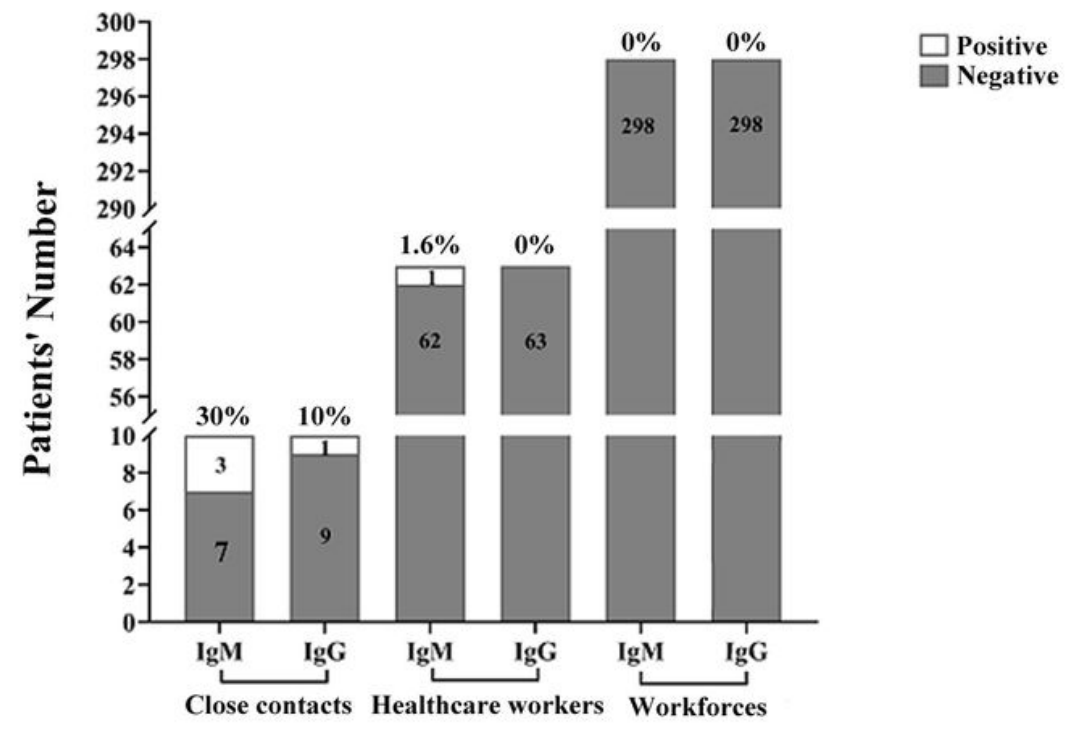

Figure 4

Population screening with rapid IgM-IgG combined antibody test for SARS-CoV 2 in peripheral blood. A was a picture showed the screening site. B shows the screening results, including Close contacts, healthcare workers and workforces.

\section{Supplementary Files}

This is a list of supplementary files associated with this preprint. Click to download.

- SupplementaryTable.docx 